\title{
Integration of quantitative analysis and local community involvement for wildfire risk mapping: a case study from an Alpine valley
}

\author{
Ingrid Vigna $^{\mathrm{a},}$ *, Angelo Besana ${ }^{\mathrm{a}}$, Elena Comino ${ }^{\mathrm{b}}$, Alessandro Pezzoli ${ }^{\mathrm{a}}$, Davide Ascoli ${ }^{\mathrm{c}}$ \\ ${ }^{a}$ Interuniversity Department of Regional and Urban Studies and Planning (DIST), Politecnico di Torino \& Università di Torino, \\ ingrid.vigna@polito.it,angelo.besana@unito.it, alessandro.pezzoli@polito.it \\ ${ }^{b}$ Department of Environment, Land and Infrastructure Engineering (DIATI), Politecnico di Torino, elena.comino@polito.it \\ ${ }^{c}$ Department of Agricultural, Forest and Food Sciences (DISAFA), Università di Torino, d.ascoli@ unito.it \\ * Corresponding author
}

Keywords: Wildfire risk, participatory mapping, FlamMap, ecosystem services, vulnerability

\begin{abstract}
:
Forest ecosystems provide a wide range of fundamental ecosystem services (ES), ranging from the water cycle regulation to the supply of wood and food. Natural disturbances, such as wildfires, might compromise ES maintenance and delivery. Although fire is an intrinsic process in most forest biomes, climate and land use changes are altering historical fire regimes (e.g., frequency, intensity, severity) with uncertain impacts on ES. In this contest, wildfire risk assessment and mapping to support prevention and mitigation actions has become urgent.
\end{abstract}

The analysis of the existing literature reveals a number of different approaches used for wildfire risk assessment, such as fire modelling systems (e.g. simulators of fire behaviour and effect), cost-benefit analysis, expert analysis and social media data analysis. However, an exhaustive definition of risk is often lacking. Moreover, most of previous studies focus on the risk for human assets (Mahmoud and Chulahwat, 2020) or for the provision of a specific forest ecosystem service (Lecina-Diaz at al, 2021), while a more comprehensive methodology is still missing. This study, therefore, aims at developing a robust and versatile procedure for wildfire risk assessment and mapping, able to adapt to the specific characteristics of the forest socio-ecological system analysed thanks to the involvement of the local community in the cartographic process (Ager et al., 2015; Devisscher et al, 2016). The methodology is based on the innovative integration of interviews and focus groups approaches with wildfire behaviour simulations and indicators mapping, through the support of Geographical Information Systems instruments.

The methodology proposed is tested in a South-Western European Alpine valley (Valchiusella, 14258 ha), a mountain area located in northern Italy exposed to frequent large fires. The wildfire regime of the area is characterized by winter fires (from October to April), which affect an average of 220 ha per year. According to past data, no fires occurred during summer, which is the rainiest season, in the period 2001-2019. The average size of the fires was about 74 ha, but exceptionally events occurred, which reached 624 ha.

Following the definition provided by the IPCC, the risk is here intended as resulting from the interaction of hazard, exposure and vulnerability (Cardona et al, 2012). The hazard is mapped with the support of FlamMap (Finney, 2006) software for wildfire behaviour simulation. The regional forest map, the high-resolution data on species distribution from the local forestry consortium, the regional digital terrain model and the Copernicus tree canopy cover are used as input information for the landscape characterization. FlamMap simulation returns the burn probability (proportional to the expected number of times a pixel is burnt under a given simulation setting) and the potential fireline intensity for each pixel, which are combined to obtain the estimated hazard.

The exposure mapping refers both to human infrastructures and to forest ES, which are classified according to the Millennium Ecosystem Assessment: provisioning services, regulating services, cultural services and supporting services. For human infrastructures, roads and buildings are considered, while a set of indicators is chosen for each class of ES. The choice of the indicators is based on the results of an interview survey carried out between January and March 2021. The interviews involved local municipal administrators, members of environmental associations, volunteer forest firefighters, forestry workers and farmers. The results helped identify the main ES provided by Valchiusella forests according to the perception of the local community. Then, based on participatory mapping, a focus group involving both local representatives and academic specialists is organized for attributing a value to the infrastructures and to the ES.

The vulnerability assessment measures the potential damage to the infrastructures and the potential loss of ability to provide ES. It is evaluated through focus group sessions and through an analytical approach, depending on the exposed element: the former is preferred, among others, for cultural ES, while the latter is preferred for provisioning ES. 
Finally, hazard, exposure and vulnerability layers are combined to obtain five maps of wildfire risk for human infrastructures and for ES provision.

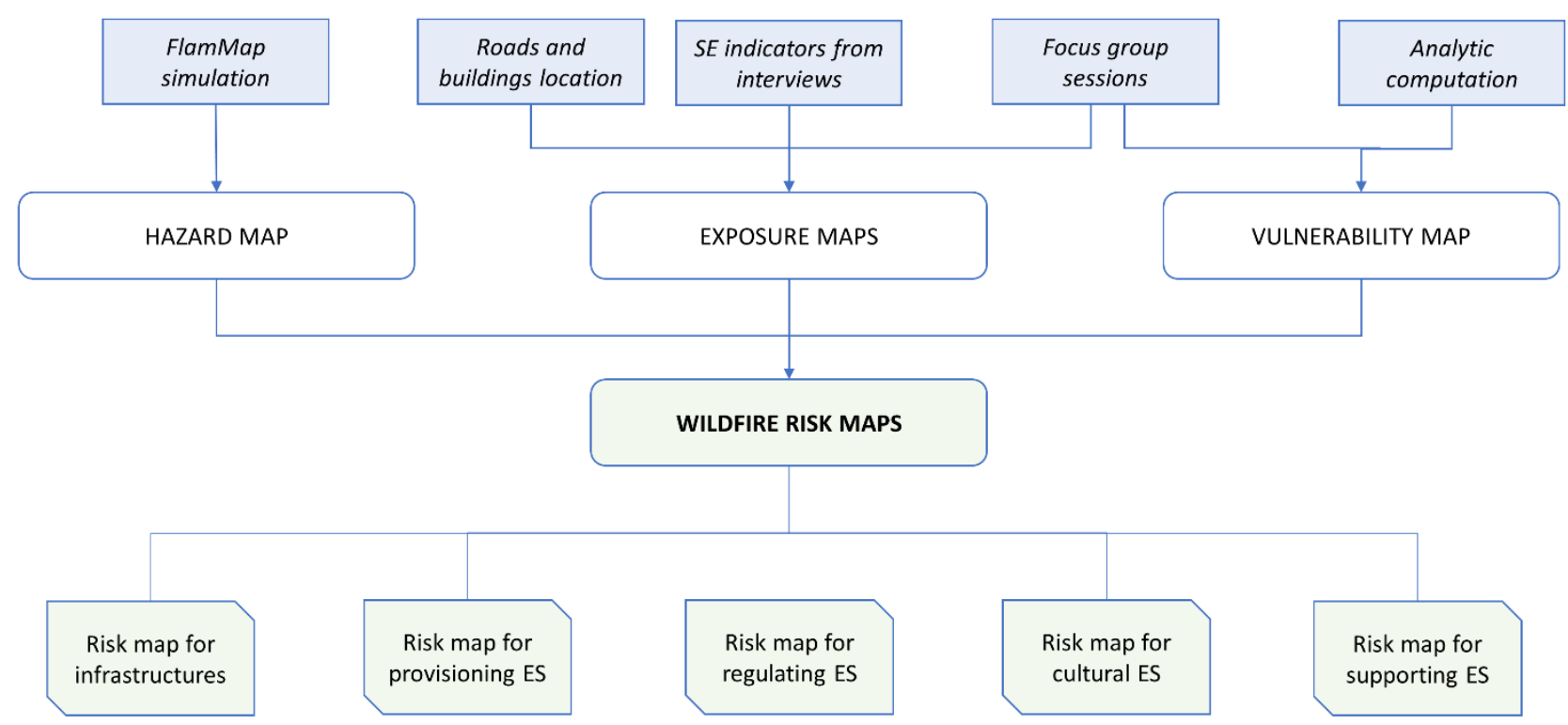

Figure 1. Schema summarizing the proposed methodology.

Preliminary results of this study allow to identify the areas with higher wildfire hazard in Valchiusella valley, supported by recorded data on past wildfire events. The exposure and vulnerability assessment will define the main areas at risk that need to be protected. This will allow to establish a prioritization of silvicultural and fuel management activities aimed at reducing the fire hazard in the area.

This multidisciplinary methodology for wildfire risk assessment bases its strength on the combination of a quantitative approach with the involvement of the local community. This allows to adapt to the local context, which is necessary for supporting the development of integrated local strategies for risk mitigation. The innovative focus on the complete range of ES, moreover, allow to address a comprehensive definition of wildfire risk and to overcome sectoral approaches.

Ager, A.A.; Kline, J.D.; Fischer, A.P. Coupling the Biophysical and Social Dimensions of Wildfire Risk to Improve Wildfire Mitigation Planning. Risk Anal. 2015, 35, 1393-1406, doi:10.1111/risa.12373.

Cardona, O.-D.; van Aalst, M.K.; Birkmann, J.; Fordham, M.; McGregor, G.; Perez, R.; Pulwarty, R.S.; Schipper, E.L.F.; Sinh, B.T. Determinants of risk: exposure and vulnerability. In: Managing the risk of extreme events and disasters to advance climate change adaptation.; Cambridge Univeristy Press: Cambridge, UK, and New York, NY, USA, 2012;

Devisscher, T.; Boyd, E.; Malhi, Y. Anticipating future risk in social-ecological systems using fuzzy cognitive mapping: The case of wildfire in the Chiquitania, Bolivia. Ecol. Soc. 2016, 21, doi:10.5751/ES-08599-210418.

Finney, M.A. An overview of FlamMap fire modeling capabilities. Fuels Manag. to Meas. Success Conf. Proc. 2006, 213-220.

Lecina-Diaz, J.; Martínez-Vilalta, J.; Alvarez, A.; Vayreda, J.; Retana, J. Assessing the Risk of Losing Forest Ecosystem Services Due to Wildfires. Ecosystems 2021, doi:10.1007/s10021-021-00611-1.

Mahmoud, H.; Chulahwat, A. Assessing wildland-urban interface fire risk. R. Soc. Open Sci. 2020, 7, 201183, doi:10.1098/rsos.201183. 